\title{
High Antiplasmodial Activity of Golden Gamat (S.hermanni) Extract Through In Vitro Study
}

\author{
Prawesty Diah Utami and Varidianto Yudho
}

\section{ABSTRACT}

\begin{abstract}
S.hermanni is a marine biota that contains active components that are antifungal, anti-bacterial, antioxidant, anti-inflammatory, and anti-cancer. The research focused on examining the antiplasmodial activity of an ethanol extract of $S$. hermanni on the proliferation of $P$. falciparum in vitro. The total sample size was 30 mediums, which included: (G1). No extract or chloroquine administration in the $P$.falciparum medium (G2). Chloroquine treatment administration on $P$. falciparum medium (G3). $P$. falciparum medium with $S$. hermanni extract. Parasitaemia, growth percentage, inhibitory rate, and IC50 were among the parameters evaluated. Administration of extract serial doses succeeds in reducing the percentage of parasite growth and parasitemia levels. G3 demonstrated an inhibitory rate of $88.51 \%$ with a dose of $100 \mu \mathrm{g} / \mathrm{ml}$ and an $\mathrm{IC}_{50}$ of $2.86 \mu \mathrm{g} / \mathrm{ml}$, indicating high antimalarial activity, although chloroquine had greater antimalarial activity than $S$. hermanni extract. In vitro studies on $S$ hermanni, ethanol extract indicated that it contains bioactive components and can be an effective antiplasmodial agent.
\end{abstract}

Published Online: September 10, 2021

ISSN: $2684-5199$

DOI: 10.24018 /ejbio.2021.2.5.260

\section{Prawesty Diah Utami*}

Departement of Parasitology, Universitas Hang Tuah, Indonesia.

(e-mail: prawesty.diah@ ${ }^{\circledR}$ hangtuah.ac.id) Varidianto Yudho

Departement of Microbiology, Universitas Hang Tuah, Indonesia.

(e-mail: vartiara@ gmail.com)

*Corresponding Author

Keywords: Antiplasmodial activity, in vitro, P.falciparum, S.hermanni.

\section{INTRODUCTION}

Malaria is a fatal illness induced by blood protozoan parasites transmitted through female Anopheles species [1]. Malaria remains a global health issue; malaria cases worldwide totaled 228 million, with Africa and Southeast Asia accounting for most cases. In 2018, the global death rate was 405 thousand fatalities[2]. Antimalarial drug resistance has led to an increase in malaria mortality rates over the past 20 years[3]. One potential source of new antimalarial drugs is compounds derived from marine biota. The world's marine, the pharmaceutical agency confirms the great potential of marine species as a source for developing new pharmaceutical components and drugs. Land biota has much lower phylogenetic diversity than marine and freshwater biota. A variety of environmental factors influences the ability of marine biota to adapt [4], [5].

Sticophus hermanni, or golden gamat, includes various bioactive substances such as chondroitin sulfate, polysaccharides, glycosaminoglycans, saponins, peptides, sterols, phenolics, and cerebrosides [4]-[6]. Numerous research has revealed that golden gamat contains biological activities such as wound healing, pain relief, antibacterial, antifungal, antioxidant, cytotoxic, and anticancer effects. [4], [6], [7]. S.hermanni's antiplasmodial effect has never been investigated. The purpose of this research was to evaluate the antiplasmodial activity of golden gamat ( $S$. hermanni) ethanol extraction Plasmodium falciparum proliferation. The research approach used in this study was an in vitro investigation with P.falciparum-containing media. The study outcomes are expected to provide scientific knowledge regarding the antiplasmodial activity of golden gamat $(S$. hermanni) extraction the growth of $P$. falciparum in vitro, which may be used as a conceptual framework for in vivo research.

\section{METHODS}

\section{A. Study Design and Setting}

The research was conducted using an experimental study with in vitro methods. The study was performed using a posttest-only control group design because we tested the parameters in all groups during the end of treatments. The researcher was conducted in vitro study at the Institute of Tropical Diseases, Airlangga University, Surabaya, Indonesia, from March to July 2021. The ethics committee of Faculty Medicine, Universitas Hang Tuah conducted a research ethics review (I/208/UHT.KEPK.03/III/2021).

\section{B. Experimental Unit}

This study's experimental unit consists of $30 P$. falciparum culture mediums. The experimental unit will be divided into the following three groups:

1). G1 consists of ten $P$. falciparum culture mediums without any antimalaria drugs (chloroquine).and extract.

2). G2 consists of ten P.falciparum culture mediums with antimalarial drugs (chloroquine).

3). G3 consists of ten P.falciparum culture mediums with the administration of $S$. hermanni ethanol extract. 
Study groups G2 and G3, administration of chloroquine and S.hermanni extract will be separated into five dose groups: 100, 10, 1, 0.1, and $0.01 \mu \mathrm{g} / \mathrm{ml}$ [8]. Each dose will be repeated twice, resulting in 10 mediums with five different doses in each group. This study obtained $P$.falciparum culture mediums from the Tropical Disease Center at Universitas Airlangga, Surabaya, Indonesia.

\section{S.hermanni Material}

The researchers performed this study using fresh golden gamat S.hermanni from the waters around the island of Sapeken, Madura-East Java, Indonesia, during the rainy season, and taxonomic testing at the Laboratory of Plant Bioscience and Technology, Sepuluh November Institute of Technology Surabaya, Indonesia (No. 002/IT.1/Biosains dan Teknologi Tumbuhan/2021). S. hermanni was extracted at the Faculty of Veterinary Medicine, Universitas Airlangga, Indonesia.

\section{Phytochemical Assay}

Phytochemical analysis was carried out to evaluate several bioactive components found in the crude extract of $S$. hermanni. Phytochemical testing can detect bioactive components in primary metabolites that induce functional biological activity[9]. The phytochemical test in this study used a qualitative method to assess the presence of an active component. We used three methods to assess the alkaloid content: Dragendroff/test Kraut's (using Dragendroff reagent - potassium, bismuth, and iodide solution and marked by the development of a red-orange precipitate); Meyer test (with Meyer's reagent - potassium mercuric iodide solution and characterized by the formation of a white precipitate). And the Wagner test (distinguished by the formation of brown precipitate from Wagner's reagent, which is an iodine solution in potassium iodide) [9]. Flavonoid test (using lead acetate - lead acetate solution and characterized by the production of an orange precipitate); tannin concentration is determined using the Braymer test, which yields a greenishblue liquid. Saponin content test using froth test-dilution with distilled water for 15 minutes, followed by froth formation on the surface. The steroid content was evaluated using concentrated $\mathrm{H}_{2} \mathrm{SO}_{4}$ and chloroform, and we noticed a red color change under the chloroform layer. As previously stated, conventional procedures and methods are used in other fields [9]-[11].

\section{E. Ethanol Extraction}

The golden gamat $S$ hermanni was cleaned, sliced into small pieces, and dried. After drying, gold sea cucumber pieces are mashed to make $900 \mathrm{~g}$ of gold sea cucumber powder. The powder is extracted using a maceration process with $96 \%$ ethanol $(3000 \mathrm{ml})$. The resultant macerate was collected and evaporated using a rotary evaporator under vacuum, yielding a viscous extract of 45 grams of golden sea cucumber ethanol extract, which was deposited in an airtight container and refrigerated until use [12].

\section{F. Plasmodium falciparum Cultivation In Vitro}

The cultivation process requires the use of two primary ingredients, such as $P$. falciparum strain 3D7 (chloroquinesensitive strain) provided by Malaria Laboratory - Institute of Tropical Disease, Airlangga University, Surabaya, and also
Surabaya red cross provided human blood (packed red cell and plasma) from the Red Cross in Surabaya, Indonesia. In vitro study was conducted to evaluate the antimalarial effect applying a modified Trager and Jensen technique. The parasites were cultivated in fresh human erythrocytes (with blood type $\mathrm{O}$ positive, male) up to $5 \%$ hematocrit and planted in RPMI 1640 media. We added hypoxanthine to the RPMI 1640 medium at a concentration of 50 micrograms per milliliter, together with $2 \mathrm{mg} / \mathrm{mL} \mathrm{NaHCO} 3,25 \mathrm{mM}$ HEPES buffer, and ten micrograms/milliliter gentamycin. Then we put the culture inside a modified candle jar and incubated it at $37{ }^{\circ} \mathrm{C}$. [3], [13], [14]. A thin blood smear stained with Giemsa is evaluated to confirm $P$. falciparum growth. A microscope with a magnification of 1000 times was used to observe the infected erythrocytes. The parasite utilized in the test is synchronized (ring form stage) with an approximated parasitemia level of $1 \%$. (hematocrit $5 \%$ ) [13].

\section{G. In Vitro Antiplasmodial Activity Assay}

The extract $(10 \mathrm{mg})$ and chloroquine were diluted in 1000 ul of DMSO (to form a 10,000 ug/ml). From the stock solution, serial dilutions were made, providing a homogeneous solution of $0.01 ; 0.1 ; 1 ; 10 ; 100$ micrograms per milliliter[3]. Each microwell (well 96) received 2 ul of extract solution (for G3 groups) and chloroquine (for G2 groups) at varying doses (dosage gradation $0.01 ; 0.1 ; 1 ; 10$; and 100 micrograms per milliliter), followed by 1981 of parasite cell suspension (we made each concentration in duplicate). The parasite suspension was the only component in the negative control well (G1), with no extract or chloroquine added. The well containing the extract liquid and parasites was placed into a mixture of five percent oxygen, five percent carbon dioxide, and ninety percent of nitrogen and maintained around $37{ }^{\circ} \mathrm{C}$ for 48 hours. We checked parasite cell cultures for thin blood smears to indicate parasitemia before being injected into the microwell (parasitemia levels at -0 hours). Following culture harvesting, a thin blood film was produced using $10 \%$ Giemsa staining [3], [15]. The data was analyzed using light microscopy, and we calculated the number of infected red blood cells per one thousand red blood cells [16] (data on parasitemia levels after treatment/data at -48 hours). The researcher will use this information to calculate parasitemia growth and inhibition percentages. The percentage of growth and the inhibitory rate was calculated using the following [3]:

$\%$ growth $=\%$ parasite after treatment $-\%$ parasite before treatment

$$
\% \text { Inhibitory }=\frac{100 \%-\% \text { growth on experimental group }}{\% \text { growth on negative control group }} \times 100 \%
$$

The final stage in assessing the antiplasmodial activity of S.hermanni extract was to estimate the $\mathrm{IC}_{50}$. A statistical analysis based on the percent inhibitory rate was performed using probit analysis and the SPSS version 20 software. $\mathrm{IC}_{50}$ is a measurement used in pharmacological research to determine the dose of drug/active ingredient necessary to inhibit biological processes by $50 \%$, and it serves as a measure of the drug/active ingredient's potency [17], [18]. Probit analysis is a subset of regression analysis in which the concentration-response curve is converted into a straight line 
and it serves as a measure of the drug/active ingredient's potency [17], [18]. Probit analysis is a subset of regression analysis in which the concentration-response curve is converted into a straight line that can then be examined using least squares or maximum likelihood regression [19].

\section{H. In vitro Antiplasmodial Activity Criteria}

In this study, we analyzed the $\mathrm{IC}_{50}$ results to WHO standard requirements for antimalarial drug development projects, and the extract materials were grouped into different groups based on their $\mathrm{IC}_{50}$ :

1) High potency if $\mathrm{IC}_{50}$ value less than or equal to $5 \mu \mathrm{g} / \mathrm{ml}$.

2) promising potency if $\mathrm{IC}_{50}$ value greater than $5 \mu \mathrm{g} / \mathrm{ml}$ or less than or equal to $5 \mu \mathrm{g} / \mathrm{ml}$.

3) moderate potency if $<\mathrm{IC}_{50}$ value greater than $15 \mu \mathrm{g} / \mathrm{ml}$, or less than or equal to $50 \mu \mathrm{g} / \mathrm{ml}$.

4) If the IC50 value is larger than 50 micrograms per milliliter, the potency is poor.

A pure material is deemed very active when its $\mathrm{IC}_{50}$ value is less or equal $1 \mu \mathrm{g} / \mathrm{ml}$. [3].

\section{Statistical Analysis}

Data from parasitaemia level measurements were processed in excel software to calculate percent parasitaemia growth and percent inhibitory rate. $\mathrm{IC}_{50}$ analysis using Probit analysis in SPSS version 20 software.

\section{RESULT}

\section{A. Phytochemical Assay}

Qualitative phytochemical assays to establish active compounds in ethanol extract of S.hermanni. According to the phytochemical test, the ethanol extract of S. hermanni includes various active compounds, including flavonoids, saponins, steroids, and alkaloids, but not tannins.

\section{B. In Vitro Antimalarial Activity Assay}

The parasitemia level was determined twice: before treatment (at 0 hours) and after treatment and incubation (at 48 hours). Data on parasitemia levels at 0 hours revealed homogenous findings in each treatment group, $1.03 \%$. After 48 hours of incubation and treatment, parasitemia levels were measured and found to be varied. The following table shows the results of measuring the parasitemia level in $S$ hermanni extract with ethanol solvent:

TABLE I: PARASITEMIA LEVEL ASSAY

\begin{tabular}{lcccccc}
\hline \multirow{2}{*}{ Groups } & 0 & \multicolumn{5}{c}{$\%$ Parasitemia at 48 Hours } \\
\cline { 3 - 7 } & hours & $100^{*}$ & $10^{*}$ & $1^{*}$ & $0.1^{*}$ & $0.01^{*}$ \\
\hline control (-) & 1,03 & 6,73 & 6,73 & 6,73 & 6,73 & 6,73 \\
control (+) & 1,03 & - & 1,46 & 2,09 & 2,79 & 3,67 \\
Ethanol - & 1,03 & 1,685 & 3,23 & 4,64 & 5,8 & 6,475 \\
S.hermanni & & & & & &
\end{tabular}

*: all doses in micrograms per milliliter.

According to the table above, the level of parasitemia in the treatment group (control positive and ethanol extract of $S$ hermanni) decreased with increasing doses of extract and chloroquine. According to the table above, the level of parasitemia in the treatment group (control positive and ethanol extract of $S$ hermanni) decreased with increasing doses of extract and chloroquine. We did not measure parasitemia level on the $\mathrm{G} 2$ group/control positive group at a concentration of $100 \mu \mathrm{g} / \mathrm{ml}$ because the parasitemia level was very low at ten micrograms/milliliter.

The following figure describes the parasitemia increase percentage obtained from the difference between parasitemia levels at 0 and 48 hours:

TABLE II: PARASITE GROWTH ASSAY

\begin{tabular}{lccccc}
\multicolumn{5}{c}{ TABLE II: PARASITE GROWTH ASSAY } \\
\cline { 2 - 6 } \multicolumn{1}{c}{ Groups } & $100^{*}$ & $10^{*}$ & $1^{*}$ & $0.1^{*}$ & $0.01^{*}$ \\
\hline control (-) & 5,7 & 5,7 & 5,7 & 5,7 & 5,7 \\
control (+) & - & 0,43 & 1,06 & 1,76 & 2,64 \\
Ethanol - & 0,65 & 2,2 & 3,61 & 4,77 & 5,44 \\
S.hermanni & & & & &
\end{tabular}

The data from parasite growth measurements revealed that the higher the amount of chloroquine and S.hermanni extract administered, the slower the parasite grew. We did not assess the parasite growth rate in the positive control group at 100 $\mu \mathrm{g} / \mathrm{ml}$ because it was nearly zero at $10 \mu \mathrm{g} / \mathrm{ml}$. Among the other groups, the lowest dose of chloroquine $(0.01 \mu \mathrm{g} / \mathrm{ml})$ up to $10 \mu \mathrm{g} / \mathrm{ml}$ shown the least amount of parasite development

The following table summarizes the findings of the inhibitory rate measurement and probit analysis of the positive control and S.hermanni extract with ethanol:

TABLE III: INHIBITORY RATE \& IC 50 ASSAY RESULT

\begin{tabular}{ccccccc}
\hline \multirow{2}{*}{ Groups } & $\mathrm{IC}_{50}$ & \multicolumn{5}{c}{ \% Inhibitory Rate } \\
\cline { 3 - 7 } & $(\mu \mathrm{g} / \mathrm{ml})$ & $100^{*}$ & $10^{*}$ & $1^{*}$ & $0.1^{*}$ & $0.01^{*}$ \\
\hline control (+) & 0,005 & - & 92,46 & 81,40 & 69,12 & 53,68 \\
Ethanol - & 2,86 & 88,51 & 61,40 & 36,67 & 16,32 & 4,47 \\
S.hermanni & & & & & &
\end{tabular}

According to the table above, increasing doses of chloroquine and S.hermanni extract enhance the inhibitory rate. Because the negative control group only contained P.falciparum without any treatment, we did not measure the inhibitory rate. The inhibitory rate in the positive control group at a concentration of $10 \mu \mathrm{g} / \mathrm{ml}$ was about $100 \%$, the highest compared to the other groups. Chloroquine has a lower IC50 than S.hermanni's ethanol extract; these results suggest that chloroquine has a higher potency (IC50 $\leq 5 \mu \mathrm{g} / \mathrm{ml}$ ) than S.hermanni's ethanol extract. However, compared to WHO guidelines, ethanol extract of S.hermanni showed high antimalarial activity (high potency if IC50 $\leq$ $5 \mu \mathrm{g} / \mathrm{ml})$.

\section{DISCUSSION}

The phytochemical assay in this study differed from the previous study by Pringgenies et al. (2018), who discovered that $S$ hermanni contains flavonoids, saponins, steroids, tannins, and terpenoids but no alkaloids [18]. The different result is most likely due to the sampling location of S.hermanni, which differs in location. Location dissimilarities may result in different environmental exposures and adaptive mechanisms, resulting in variable types and amounts of active compounds. Other parameters that significantly impact extraction efficiency include extraction method, temperature, duration of the extraction process, and solvent applied. If the extraction procedure is the same, the solvent selected will significantly impact the bioactive content [20]. because each solvent has a different 
polarity (polar, semipolar, and nonpolar)[21]. The solvent type and polarity also influence extraction quality, amount, extraction velocity, inhibition chemicals, toxicology, other bioactivities, and biosecurity [21], [22].

This research suggests that an ethanol extract of $S$. hermanni could inhibit the growth of $P$. falciparum in culture media. These findings are consistent with the findings of Sarhadizadeh et al. [6] who found that S. hermanni extract demonstrated antifungal action, with suppression of fungal growth activity rising with increasing extract dose, but no antibacterial activity. Another study found that S. hermanni extract has antibacterial properties against $S$. aureus, Pseudomonas sp, E.coli, and other bacteria. Another study found that $S$. hermanni extract had an antibacterial effect against $S$. aureus, Pseudomonas sp, E.coli, and V. vulnificus [18]. There has been no research on the antimalarial activity of $S$. hermanni extract; thus, no data can be compared.

Based on the inhibitory rate and $\mathrm{IC}_{50}$ values, $S$. hermanni extract had a high potential antimalarial activity but was less potent than chloroquine. The antimalarial activity of S.hermanni extract is attributed to the presence of several active components. Through phytochemical assay on this research, the antimalarial action of $S$. hermanni extract was linked to different active compounds, including flavonoids, saponins, steroids, and alkaloids. Flavonoids have been found to have antimalarial effects via reducing hemoglobin breakdown by blocking the action of the cysteine protease enzyme falcipain-2 [3]. The saponins also have an antimalarial impact by damaging the cell membranes of infected erythrocytes, causing erythrocyte cells to lyse [23], [24]. Alkaloids have been proven to reduce parasitemia levels by suppressing parasite DNA and RNA production ${ }^{25}$. S.hermanni extract contains a steroid as the final product. Several investigations have found that steroids and their derivatives have antimalarial properties; however, the mechanism is unknown [26], [27]. Krieg et al. [28] have shown that arylmethylamino steroids are particularly effective antiplasmodial components due to their capacity to impede transmission, oral availability, and minimal toxicity. The inclusion of lipophilic steroid carriers to this antiparasitic aids in mediating cellular uptake and intracellular transport pathways, improving the antiparasitic's potency. Estratriene, a steroid derivative, works as an antiplasmodial agent by boosting cellular oxidation [28]. S. hermanni extract's mechanisms of action against malaria parasites require further study.

\section{CONCLUSION}

S. hermanni extract with ethanol solvent had the highest inhibitory rate of $88.51 \%$ with a dose of $100 \mu \mathrm{g} / \mathrm{ml}$ and an $\mathrm{IC}_{50}$ of $2.86 \mu \mathrm{g} / \mathrm{ml}$ (referring to the WHO guidelines, this figure indicates a high potential for antimalarial activity), although its activity is lower than chloroquine. S hermanni ethanol extract's antimalarial activity was associated with a phytochemical assay result, which indicated diverse bioactive components such as alkaloid, flavonoid, saponin, and steroid. Previous studies have shown that each of these bioactive components has its function and mechanism for suppressing the growth of $P$. falciparum through in vitro and in vivo studies. Based on the results of this study, further studies are needed to explore the antimalarial activity of S. hermanni.

\section{ACKNOWLEDGMENT}

There is no conflict of interest in the publication of the paper. The author would like to express his gratitude to Hang Tuah University's medical faculty for supporting the research and publication. We'd also want to thank the Tropical Disease Institute's Malaria Laboratory for supplying instruments, resources, and conducting research, as well as everyone who helped us finish this project.

\section{REFERENCES}

[1] A. Mousa et al., "The impact of delayed treatment of uncomplicated P. falciparum malaria on progression to severe malaria: A systematic review and a pooled multicentre individual- patient meta-analysis," Plos Med., vol. 17, no. 10, pp. 1-28, 2020, doi: 10.1371/journal.pmed.1003359.

[2] World Health Organization, World Malaria Report 2019. Geneva. 2019, pp xii-xiii.

[3] A. R. Hidayati et al., "Antimalarial activity of flavonoid compound isolated from leaves of artocarpus altilis," Pharmacogn. J., vol. 12, no. 4, pp. 835-842, 2020, doi: 10.5530/pj.2020.12.120.

[4] Y. Khotimchenko, "Pharmacological Potential of Sea Cucumbers," Int. J. Mol. Scinces, vol. 19, no. 1342, pp. 1-42, 2018, doi: 10.3390/ijms19051342.

[5] A. Rasyid, Y. Yasman, and M. Y. Putra, "Current prospects of nutraceutical and pharmaceutical use of sea cucumbers," Pharmacia, vol. 68, no. 3, pp. 561-572, 2021, doi: 10.3897/pharmacia.68.e69140.

[6] N.Sarhadizadeh, M.Afkhami, and M.Ehsanpour, "Evaluation bioactivity of a Sea cucumber, Stichopus hermanni from Persian Evaluation bioactivity of a Sea cucumber, Stichopus hermanni from Persian Gulf," Eur. J. Exp. Biol., vol. 4, no. 1, pp. 254-258, 2014.

[7] K. Parasihni and S. Revianti, "Antifungal effect of Sticophus hermanii and Holothuria atra extract and its cytotoxicity on gingiva-derived mesenchymal stem cell," Dent. J., vol. 46, no. 4, pp. 218-223, 2013.

[8] E. Setyaningrum, A. Arifiyanto, N. Nukmal, T. N. Aeny, M. handerlin Putri, and U. N. mah Setiawati, "In vitro test for inhibition of Plasmodium falciparum $3 \mathrm{~d} 7$ parasites using streptomyces hygroscopicus subsp. hygroscopicus strain i18, isolated from a Pineapple Farm in lampung," J. Pure Appl. Microbiol., vol. 15, no. 2, pp. 891-896, 2021, doi: 10.22207/JPAM.15.2.45.

[9] J. R. Shaikh and M. Patil, "Qualitative tests for preliminary phytochemical screening: An overview," Int. J. Chem. Stud., vol. 8, no. 2, pp. 603-608, 2020, doi: 10.22271/chemi.2020.v8.i2i.8834.

[10] R.Kurnijasanti and M.Candrarisna, "The effect of pisang ambon (Musa paradisiaca L.) stem extract on the regulation of IL-1ß, IL-6 and TNF$\alpha$ in rats' enteritis," Iraqi J. Vet. Sci., vol. 33, no. 2, pp. 407-413, 2019 , doi: 10.1093/carcin/bgs062.

[11] E. Damayanti, J. Widada, P. D. N. Lotulung, A. Dinoto, and Mustofa, "Bioassay guided fractionation of marine streptomyces sp. GMY01 and antiplasmodial assay using microscopic and flow cytometry method," Indones. J. Pharm., vol. 31, no. 4, pp. 281-289, 2020, doi: 10.22146/ijp.809.

[12] S. D. Desai, D. G. Desai, and H. Kaur, "Saponins and their biological activities," Pharma Times, vol. 41, no. 3, pp. 13-16, 2009.

[13] P. A. Kweyamba, D. Zofou, N. Efange, J. C. N. Assob, J. Kitau, and M. Nyindo, "In vitro and in vivo studies on anti-malarial activity of Commiphora africana and Dichrostachys cinerea used by the Maasai in Arusha region, Tanzania," Malar. J., vol. 18, no. 1, pp. 1-6, 2019, doi: 10.1186/s12936-019-2752-8.

[14] M. Zakiah, R. A. Syarif, M. Mustofa, J. Jumina, N. Fatmasari, and E. N. Sholikhah, "In Vitro Antiplasmodial, Heme Polymerization, and Cytotoxicity of Hydroxyxanthone Derivatives Mistika," J. Trop. Med., vol. 2021, no. 8866681, pp. 1-11, 2021.

[15] I. Indriani, N. S. Aminah, and N. N. T. Puspaningsih, "Antiplasmodial Activity of Stigmastane Steroids from Dryobalanops oblongifolia Stem Bark," Open Chem., vol. 18, no. 1, pp. 259-264, 2020, doi: 10.1515/chem-2020-0027.

[16] J. Gomis-Tena et al., "When Does the IC50Accurately Assess the Blocking Potency of a Drug?," J. Chem. Inf. Model., vol. 60, no. 3, pp. 1779-1790, 2020, doi: 10.1021/acs.jcim.9b01085.

[17] J. Pum, A practical guide to validation and verification of analytical 
methods in the clinical laboratory, 1st ed., vol. 90. Elsevier Inc., 2019.

[18] D. Pringgenies, S. Rudiyanti, and E. Yudiati, "Exploration of Sea Cucumbers Stichopus hermanii from Karimunjawa Islands as Production of Marine Biological Resources," IOP Conf. Ser. Earth Environ. Sci., vol. 116, no. 1, 2018, doi: 10.1088/17551315/116/1/012039.

[19] D. H. Truong, D. H. Nguyen, N. T. A. Ta, A. V. Bui, T. H. Do, and H. C. Nguyen, "Evaluation of the use of different solvents for phytochemical constituents, antioxidants, and in vitro antiinflammatory activities of severinia buxifolia," J. Food Qual., vol. 2019, no. 8178294, pp. 1-10, 2019, doi: 10.1155/2019/8178294.

[20] M. L. Chávez-González et al., "Conventional and emerging extraction processes of flavonoids," Processes, vol. 8, no. 434, pp. 1-29, 2020, doi: 10.3390/PR8040434.

[21] A. Wakeel, S. A. Jan, I. Ullah, Z. K. Shinwari, and M. Xu, "Solvent polarity mediates phytochemical yield and antioxidant capacity of Isatis tinctoria," PeerJ, vol. 2019, no. 10, pp. 1-19, 2019, doi: $10.7717 /$ peerj.7857.

[22] N. El Houda Lezoul, M. Belkadi, F. Habibi, and F. Guillén, "Extraction processes with several solvents on total bioactive compounds in different organs of three medicinal plants," Molecules, vol. 25, no. 4672, pp. 1-15, 2020, doi: 10.3390/molecules25204672.

[23] M. A. Ungogo, G. U. Ebiloma, N. Ichoron, J. O. Igoli, H. P. de Koning, and E. O. Balogun, "A Review of the Antimalarial, Antitrypanosomal, and Antileishmanial Activities of Natural Compounds Isolated From Nigerian Flora," Front. Chem., vol. 8, no. 617448, pp. 1-28, 2020, doi: 10.3389/fchem.2020.617448.

[24] M. M. A. El Aziz, A. S. Ashour, and A. S. G. Melad, "A review on saponins from medicinal plants: chemistry, isolation, and determination," J. Nanomedicine Res., vol. 7, no. 4, pp. 282-288, 2019, doi: 10.15406/jnmr.2019.07.00199.

[25] J. Talapko, I. Škrlec, T. Alebi, M. Juki, and A. V`cev, "Malaria: The Past and the Present," Microorganisms, vol. 7, no. 179, pp. 1-17, 2019

[26] P. F. Uzor, "Alkaloids from Plants with Antimalarial Activity: A Review of Recent Studies," Hindawi 2 Evidence-Based Complement. Altern. Med., vol. 2020, pp. 1-17, 2020.

[27] M. Fadaeinasab, H. Taha, P. N. M. Fauzi, H. M. Ali, and A. Widyawaruyanti, "Anti-malarial Activity of Isoquinoline Alkaloids from the Stem Bark of Actinodaphne macrophylla," Nat. Prod. Commun., vol. 10, no. 9, 2015, doi: 10.1177/1934578X1501000913.

[28] R. Krieg et al., "Arylmethylamino steroids as antiparasitic agents," Nat. Commun., vol. 8, no. 14478, pp. 1-14, 2017, doi: $10.1038 /$ ncomms 14478 .

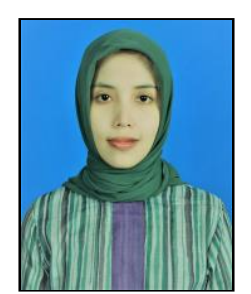

Prawesty Diah Utami was born in Surabaya on October 28, 1978. She started her medical studies at Airlangga University in 1997 and graduated in 2003. In 2010, she completed a master's degree program at Airlangga University's Faculty of Medicine. Then, she obtained her Ph.D. from Airlangga University's Faculty of Medicine in 2019. Since 2005, the author has worked as a lecturer and researcher in the Parasitology Department at Hang Tuah University's Faculty of Medicine. She has published numerous scientific works, the most recent of which was published in August 2021 under the title "Protection against Brain histopathological damage in experimental Cerebral malaria models exposure to hyperbaric oxygen.". The author is interested in numerous scientific areas, including infectious diseases, immunology, molecular biology, and hyperbaric oxygen.

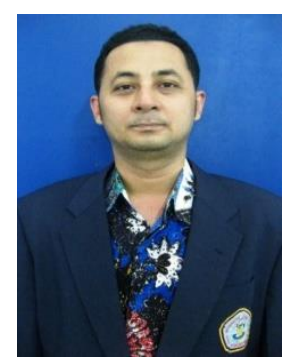

Varidianto Yudho was born on the 31st of May, 1974, in Surabaya, Indonesia. He enrolled at Hang Tuah University in 1994 and graduated in 2001 with a degree in medicine. In 2008, the author graduated from Airlangga University's Faculty of Medicine with a master's degree. The author is currently pursuing a $\mathrm{Ph} . \mathrm{D}$. in doctoral program at Airlangga University. The author has been a lecturer and researcher at Hang Tuah University's Faculty of Medicine's Parasitology Department since 2003. His most recent publication, "Lethal concentration of Golden Sea Cucumber killed Vibrio cholerae," was published in August 2021. The author is enthusiastic about infectious diseases, immunology, and molecular biology. 